\title{
Vulnerabilidad social y política al VIH-sida en Bogotá*
}

[Separata]

Ismael José González-Guzmán**

Recibido: 1 de marzo de 2021

Aprobado: 7 de junio de 2021

Citar como:

González-Guzmán, I.J. (2021). Vulnerabilidad social y política al VIH-sida en Bogotá. Análisis, 53(99). https://doi.org/10.15332/21459169.6441

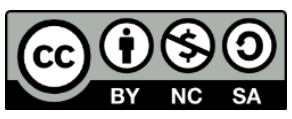

\section{Resumen}

Este estudio se propuso establecer los procesos y factores sociales que determinan la vulnerabilidad al VIH-sida y examinar el papel de la política pública para incrementar dicha vulnerabilidad social en Bogotá. El itinerario metodológico tuvo como punto de partida un enfoque cualitativo donde se articularon cuatro tradiciones de estudio (salud pública crítica; antropología crítica de la salud; sociología de la práctica médica y evaluación de políticas públicas) y varias estrategias: la investigación documental, el análisis de la política distrital y las entrevistas semiestructuradas realizadas a instituciones de salud pública y organizaciones de base comunitaria. Los resultados develaron la

\footnotetext{
* Artículo de investigación derivado de la tesis doctoral, "El VIH-sida en Bogotá: entre determinación social y razón humanitaria" que el autor presentó a la Pontificia Universidad Javeriana de Bogotá.

** Posdoctorando en Bioética, Universidad El Bosque de Bogotá; Doctor en Ciencias Sociales y Humanas, Pontificia Universidad Javeriana de Bogotá; Docente del Departamento de Humanidades y Formación Integral, Universidad Santo Tomás de Bogotá; Miembro del grupo de investigación "Bioética" del Instituto de Bioética de la Pontificia Universidad Javeriana de Bogotá; Miembro de la Red para la Formación Ética y Ciudadana. Correo electrónico:

ismaelgonzalez.com@gmail.com; ORCID: https://orcid.org/0000-0002-1869-4712
}

\section{Análisis}

ISSN: 0120-8454 | e-ISSN: 2145-9169 | DOI: https://doi.org/10.15332/21459169

Vol. 53 N.o 99 | julio-diciembre de 2021 
incapacidad política para garantizar el derecho a la vida y salud de las personas que viven con VIH-sida, eliminar el estigma, la discriminación y la violencia de género. Por tanto, se brindan algunas recomendaciones para reorientar la política pública en esta materia.

Palabras claves: Políticas públicas, VIH-sida, estigma, exclusión, vulnerabilidad social.

\section{Social and Political Vulnerability to HIV/AIDS in Bogotá}

\section{Abstract}

This study aimed to establish the processes and social factors that determine vulnerability to HIV/AIDS and to examine the role of public policy to increase said social vulnerability in Bogotá. The methodological itinerary had as its starting point a qualitative approach that articulated four traditions of study (critical public health, critical anthropology of health, sociology of medical practice and evaluation of public policies) and various strategies: documentary research, analysis of district policy, and semi-structured interviews conducted with public health institutions and community-based organizations. The results revealed the political inability to guarantee the right to life and health of people living with HIV/AIDS, to eliminate stigma, discrimination and gender-based violence. Therefore, some recommendations are provided to reorient public policy in this matter.

Keywords: Public policies, HIV/AIDS, stigma, exclusion, social vulnerability. 


\section{Vulnerabilidade social e política para HIV-Aids em Bogotá}

\section{Resumo}

Este estudo teve como objetivo estabelecer os processos e fatores sociais que determinam a vulnerabilidade ao HIV-aids e examinar o papel das políticas públicas para aumentar essa vulnerabilidade social em Bogotá. O itinerário metodológico teve como ponto de partida uma abordagem qualitativa onde se articularam quatro tradições de estudo (saúde pública crítica; antropologia crítica da saúde; sociologia da prática médica e avaliação de políticas públicas) e várias estratégias: pesquisa documental, análise da política distrital e entrevistas semiestruturadas com instituições de saúde pública e organizações comunitárias. Os resultados revelaram a incapacidade política de garantir o direito à vida $\mathrm{e}$ à saúde das pessoas que vivem com HIV/Aids, eliminar o estigma, a discriminação e a violência de gênero. Portanto, algumas recomendações são fornecidas para reorientar as políticas públicas neste assunto.

Palavras-chave: Políticas públicas, HIV-Aids, estigma, exclusão, vulnerabilidade social.

Dedicado a todos aquellos vulnerables y vulnerados que viven con VIH-sida y han sido excluidos y silenciados al margen de la historia.

\section{Introducción}

La historia del Virus de la Inmunodeficiencia Humana (VIH) y el síndrome de inmunodeficiencia adquirida (sida), comenzó a escribirse en Colombia desde el año 1983, cuando se reportó el primer caso en una mujer [Marleny], quien falleció en la ciudad de Cartagena (Ministerio de Salud y Protección Social, 2014). Para el año 2019 se habían registrado en el país 180 ooo casos de personas viviendo con VIH, 3000 muertes por sida entre 
adultos y mayores de 15 años y 67000 huérfanos por el sida de o a 17 años (Onusida, 2021). Por otro lado, en Bogotá se registraron 3955 casos de personas viviendo con VIH y 323 muertes por sida a 2019 (Saludata, 2021).

Según el Ministerio de Salud y Protección Social, las personas con mayor riesgo de exposición al virus son los "hombres que tienen relaciones sexuales con hombres, mujeres transgénero, mujeres trabajadoras sexuales, usuarios de drogas intravenosas, personas privadas de la libertad, personas en situación de calle, mujeres y jóvenes en contextos de vulnerabilidad y víctimas de violencia" (Ministerio de Salud y Protección Social, 2014, pp.16-17).

Por otro lado, el VIH-sida ha generado estigmatización y exclusión para estas poblaciones; tratos despectivos hacia ellos coinciden frecuentemente con "elementos de etiquetaje, estereotipia, separación, pérdida del estatus y discriminación en una situación de poder que permite que se desplieguen los componentes del estigma" (Link y Phelan, 2001, pp. 366367). Según dicta la Constitución Política de Colombia (1991), el Estado debe garantizar que las personas no sean sometidas a estigmatización o trato discriminatorio o degradante. Esta dice:

Nadie será sometido [...] a tratos o penas crueles, inhumanos o degradantes (art. 12). Todas las personas nacen libres e iguales ante la ley, recibirán la misma protección y trato de las autoridades y gozarán de los mismos derechos, libertades y oportunidades sin ninguna discriminación por razones de sexo, raza, origen nacional o familiar, lengua, religión, opinión política o filosófica. El Estado promoverá las condiciones para que la igualdad sea real y efectiva y adoptará medidas en favor de grupos discriminados o marginados (art. 13). Todas las personas tienen derecho a su intimidad personal y familiar y a su buen nombre, y el Estado debe respetarlos y hacerlos respetar (art. 15). Se 
garantiza el derecho a la honra. La ley señalará la forma de su protección (art. 21).

En ejercicio de dicha obligación, el Estado ha respondido con diversas leyes, decretos, resoluciones, acuerdos, circulares, programas, planes y comités que se han orientado a atender el problema de un modo fundamentalmente preventivo. En general, este encuadre del problema no solo no ha permitido elaborar un cuadro de las circunstancias sociales de las que depende el riesgo de infección o muerte por VIH-sida, ni diseñar intervenciones que las transformen, sino que ha contribuido a profundizar la vulnerabilidad misma de las personas. Por ejemplo, la estrategia del "autocuidado" ilustra el modo en que este encuadre hace abstracción de las diversas variables sociales que determinan el riesgo de exposición. Su énfasis radica en el cuidado individual basado en prácticas preventivas directas. Al respecto, el Decreto 559 de 1991 expresa:

Artículo 14: Los miembros de la comunidad tienen el deber de velar, mediante el autocuidado, por la conservación de su salud a fin de evitar la infección por el VIH; a su vez, el de concurrir a la protección de las demás personas poniendo en práctica las medidas de prevención (Presidencia de la República de Colombia, 1991).

Por su parte, la Ley Estatutaria 1751 de 2015: "Artículo 10: Son deberes de las personas relacionados con el servicio de salud [...] Propender por su autocuidado, el de su familia y el de su comunidad" (Congreso de la República de Colombia, 2015).

Esta individualización del riesgo invisibiliza las dimensiones sociales, culturales, educativas, económicas, geográficas y religiosas de las personas vulnerables a la enfermedad, a la vez que hace uniforme el modelo de prevención y control de la misma en lo urbano y en lo rural, en un estrato social alto y en las periferias subnormales de las urbes, en una comunidad 
indígena y en una afrocolombiana, etc.; parecieran bastar las mismas medidas individuales de control para todos los sectores de la población, condenando con ello a los grupos poblacionales más vulnerables a infectarse con el virus o morir por causas asociadas al sida; bien porque las condiciones sociales en las que viven constituyen barreras estructurales para que conozcan las medidas de protección, accedan a los procedimientos para la detección temprana del virus o tengan disponibilidad sostenible y eficaz del tratamiento, o bien porque la situación social global misma desincentiva el autocuidado y favorece procesos de marginación. Respecto a esto, Castro y Farmer (2003) plantean que:

Se trata de una ideología que mantiene la noción de que el tratamiento antirretroviral solo es para quien se lo pueda pagar mientras que la prevención es adecuada en todas partes. Además, [...] tienden a reproducir la manera según la cual, con frecuencia, se acusa a las personas que tienen $\mathrm{VIH} /$ sida de padecer la enfermedad, cuando en la gran mayoría de casos la enfermedad está causada por las fuerzas de una violencia estructural frente a las cuales resulta difícil desarrollar y llevar a la práctica una mínima autonomía individual o colectiva. (p. 31)

En efecto, el enfoque de este trabajo pone en cuestión este encuadre dominante, al tiempo que establece los procesos y factores sociales que determinan la vulnerabilidad al VIH-sida y examina el papel de la política pública para incrementar dicha vulnerabilidad social en Bogotá.

\section{Metodología}

Dada la naturaleza del estudio se eligió el enfoque cualitativo, que se constituye en "un proceso interpretativo de indagación basado en distintas tradiciones metodológicas que examina un problema humano o social" (Creswell, 1998, p. 255). 
Tabla 1 Políticas públicas sobre VIH-sida en Bogotá

\begin{tabular}{|c|c|}
\hline \multicolumn{2}{|r|}{ A nivel Distrital-Secretaría Distrital de Salud } \\
\hline $\begin{array}{l}\text { Decreto Distrital } 547 \text { de } \\
2016 \\
\text { [Modificó el acuerdo } 143 \\
\text { de 2005] }\end{array}$ & $\begin{array}{l}\text { Por medio del cual se fusionan y reorganizan las Instancias de Coordinación } \\
\text { con fundamento en las facultades extraordinarias otorgadas al Alcalde } \\
\text { Mayor de Bogotá por el artículo } 118 \text { del Acuerdo } 645 \text { de 2016, y se dictan } \\
\text { otras disposiciones. }\end{array}$ \\
\hline Acuerdo 641 de 2016 & $\begin{array}{l}\text { Por el cual se efectúa la reorganización del sector salud de Bogotá, distrito } \\
\text { capital, se modifica el acuerdo } 257 \text { de } 2006 \text { y se expiden otras } \\
\text { disposiciones. }\end{array}$ \\
\hline $\begin{array}{l}\text { Plan Territorial de Salud } \\
\text { 2012-2016 }\end{array}$ & $\begin{array}{l}\text { Para el cuatrienio 2012-2016, la Administración Distrital se enfrentará a } \\
\text { grandes desafíos para la transformación del sector y el alcance de mejores } \\
\text { resultados en la salud de la población de la ciudad y los millones de } \\
\text { visitantes que la elijan como destino de negocios, turismo, traslado } \\
\text { temporal o definitivo, o por circunstancias de orden social. }\end{array}$ \\
\hline $\begin{array}{l}\text { Plan Territorial de Salud } \\
2016-2020\end{array}$ & $\begin{array}{l}\text { La política distrital de salud para el cuatrienio } 20162020 \text { parte de } \\
\text { reconocer la existencia de un conjunto de políticas nacionales en torno a un } \\
\text { sistema de salud que viene operando desde } 1993 \text {, que consiste en un } \\
\text { esquema de aseguramiento social de carácter universal y obligatorio. }\end{array}$ \\
\hline
\end{tabular}

Fuente: elaboración propia a partir de información recolectada de la Alcaldía

Mayor de Bogotá (2016), el Concejo de Bogotá (2016), la Secretaría Distrital de

Salud (2012) y la Secretaría Distrital de Salud (2017).

Como tal, este enfoque permitió identificar aquellos arreglos estructurales que producen y reproducen las desigualdades que determinan la vulnerabilidad al VIH-sida. Asimismo, cuatro tradiciones se acoplaron en el desarrollo de la investigación: la salud pública crítica, la antropología crítica de la salud, los estudios sociológicos de la práctica médica y, más oblicuamente, los estudios evaluativos sobre políticas públicas respecto a la racionalidad (relevancia y pertinencia) y la coherencia (interna y externa) (Osuna y Márquez, 2000). Finalmente, se articularon varias estrategias metodológicas: la investigación documental, el análisis del contenido de la política pública a partir del estudio de archivo que usa matrices de revisión y análisis documental (ver tabla 1), y las entrevistas semiestructuradas ${ }^{1}$.

\footnotetext{
${ }^{1}$ Las instituciones y organizaciones que participaron en la investigación fueron: la Secretaría Distrital de Salud, Organización Panamericana de la Salud, Liga Colombiana de Lucha contra el sida [Ligasida], Fundación EUDES y Redsomos. A todas ellas se les compartió el instrumento que
} 


\section{Resultados}

La vulnerabilidad ha sido concebida históricamente en el marco de los derechos humanos para referirse "a aquellos a quienes se les quebrantaban sus derechos de ciudadanía” (UNFPA y Ministerio de la Protección Social, 2008, p. 13).

La vulnerabilidad se caracteriza por ser multidimensional al manifestarse en distintos individuos, grupos y comunidades en las que adopta diferentes formas y modalidades; es integral porque puede afectar todos los aspectos de la vida de quien la padece; y progresiva porque existe previamente y puede acumularse e incrementarse a través del tiempo. En este sentido es causa y consecuencia de distintas situaciones que ponen en evidencia las dificultades existentes, agudizándolas y convirtiéndolas en detonador de nuevos problemas. [...] La vulnerabilidad con respecto al VIH se encuentra en las dimensiones colectiva e individual, estando conformada la primera, a su vez, por una vulnerabilidad social y una programática. La vulnerabilidad social es el primer componente y está definida por las condiciones de mayor o menor protección de una sociedad hacia la epidemia, es decir, se focaliza sobre lo económico, lo político, lo cultural, lo moral y factores institucionales que determinarán el siguiente nivel de vulnerabilidad. [...] La vulnerabilidad programática (que está en el segundo nivel) se define por la fortaleza o la insuficiencia de los programas de prevención, control y asistencia al VIH/sida, independientemente de si provienen del ámbito gubernamental, no gubernamental o privado, y del ámbito espacial: nacional, regional o municipal. Acciones que se relacionan estrechamente con el ámbito social y determinan el individual. Tiene en cuenta el compromiso con la problemática del VIH, la existencia de acciones efectivas y coherentes con una política nacional, las coaliciones y alianzas, la capacidad de planeación y coordinación, la gestión adecuada, la respuesta a las necesidades de prevención y de tratamiento, la obtención de recursos

orientó la entrevista semiestructurada, el cual fue validado y aceptado al firmar el consentimiento informado. 
financieros, la sostenibilidad y la existencia de evaluación. En la actualidad la evaluación de la vulnerabilidad incorpora también el reconocimiento y ejercicio de los derechos humanos en las condiciones de exposición al sida, ampliando los parámetros de análisis. [...] Finalmente, en el plano micro se ubica la vulnerabilidad individual, que parte de tres presupuestos: 1) Todo individuo es vulnerable al VIH y a sus consecuencias. Esa vulnerabilidad puede variar a lo largo del tiempo en función de los valores y recursos que le permitan obtener medios para protegerse. 2) Los individuos infectados por el VIH tienen un potencial de vulnerabilidad, morbilidad, invalidez y muerte variable en función inversa al amparo social y la asistencia en salud de que disponen. 3) Las condiciones que afectan la vulnerabilidad individual son del orden Cognitivo: información, conciencia del problema y formas de enfrentarlo. Comportamentales: intereses y habilidades para transformar actitudes y acciones a partir de elementos cognitivos. Sociales: acceso a recursos y poder para adoptar comportamientos protectores. (pp. 13-17)

\section{Vulnerabilidad social al VIH-sida desde los propios afectados}

El sentir de las organizaciones de base comunitaria es que la vulnerabilidad social al VIH-sida aparece cuando: 1) la institución encargada de garantizar el derecho a la salud en Bogotá desconoce los actos administrativos [políticas públicas] que se han promulgado para responder al VIH-sida e ignora la voz de las organizaciones en las mesas técnica de VIH en el Distrito: "no tienen presente lo que decimos, somos invitados y aparecemos en una lista de asistencia, pero cuando revisamos los documentos finales nuestros aportes no están” (Entrevistado n. ${ }^{0} 4$ ). Por consiguiente, las iniciativas distritales en esta materia resultan inexistentes para los propios afectados; 2) la lógica del aparato médicosanitario individualiza el riesgo de infección, prioriza la detección temprana del virus, etiqueta a las personas con conductas de riesgo, pero 
carece de un enfoque social de vulnerabilidad, que devela las barreras que desincentivan la adherencia a los tratamientos, métodos de protección o mecanismos para la misma detección; 3) la transmisión del virus es por vía sexual, pues metafóricamente aún se considera a nivel social como un "castigo Divino" que "merece un juicio mucho más severo que otras vías de transmisión, en particular porque se entiende que el sida es una enfermedad debida no solo al exceso sexual sino a la perversión sexual" (Sontag, 2003, p. 112). En este sentido, el juicio moral que la enfermedad representa recae, principalmente, sobre los nuevos "leprosos", es decir, sobre aquellos que encarnan metafórica y existencialmente la pestilencia: los hombres que tienen relaciones sexuales con hombres [HSH], las mujeres transgénero, las trabajadoras sexuales y demás “inmorales”, para quienes se establecen unos rótulos que justifican su confinamiento en "zonas de tolerancia"2.

Bajo los efectos de estas metaforizaciones, el cuerpo mismo es producido simbólicamente como campo de batalla 3 , y la enfermedad como "agente invasor" contra el que solo vale blindarse y aislarse porque "el sida no solo es infeccioso sino además contagioso" (p. 144); aquí descansa "la capacidad social para infligir dolor sobre el Otro y [...] para hacer que el dolor del Otro sea inadmisible para el discurso público y la cultura" (Fassin, 2007, p. 12); 4) el trabajo conjunto entre instituciones y organizaciones se caracteriza por la asimetría.

En el mecanismo de coordinación país, veo muchas personas de las organizaciones que no aportan nada, no tienen fundamentación ni argumentos, luego, llegamos personas preparadas, con mucha

\footnotetext{
${ }^{2}$ Son sectores en la ciudad de Bogotá, en los que "se autorizará el ejercicio del trabajo sexual de acuerdo con la clasificación de usos del suelo que establece el Plan de Ordenamiento Territorial (POT)" (El Tiempo, 2002).

${ }^{3}$ Para Sontag (2003): "La enfermedad [VIH-sida] es vista como una invasión de organismos extraños, ante la que el cuerpo responde con sus propias operaciones militares, como la movilización de las defensas inmunológicas" (p. 96).
} 
argumentación y no es posible generar un diálogo de pares, por el contrario, generamos un respeto que apabulla y queda complejo corregir las intervenciones equivocadas. Es una participación sí, pero qué tan efectiva y verdadera sea; solo cuando sean pares en todo. (Entrevistado n. ${ }^{\circ}$ 2)

5) las políticas públicas presentan a un Estado aparentemente solidario y comprometido por dignificar la existencia de quienes padecen VIH-sida, al tiempo que refuerza la falta de garantías a sus derechos fundamentales; 6) las políticas públicas desconocen e invisibilizan las diversas realidades que acompañan la vida de los sujetos que viven con el virus.

Con todo, las organizaciones no desisten en la lucha por la defensa de sus derechos, por el contrario, han llevado el VIH-sida más allá de una cuestión biomédica-sanitarista4;

[Al VIH] lo reconocemos desde unos enfoques de vulnerabilidad individual, programática y social. En el aspecto individual, las personas no se infectan porque sí, se infectan porque no conocen o aun conociendo, asumen prácticas de riesgo que son propias del individuo; el aspecto programático, tiene que ver con el papel del Estado y su responsabilidad a través de las políticas públicas para garantizar condiciones que hagan que una persona reduzca la vulnerabilidad frente al VIH-sida, esto es: acceso a preservativos, información, campañas educativas, lubricantes, pruebas y PrEP [La profilaxis preexposición]; el aspecto social, tiene que ver con costumbres culturales, discriminación, estigma, homofobia, transfobia, pobreza, garantía de derechos de protección social que hace que una persona con mayor facilidad adquiera el virus y la inequidad de género. (Entrevistado n. ${ }^{0} 3$ )

\footnotetext{
4 "Aquí quizás radica la dificultad principal de las ciencias de la salud, ya que [...] no utiliza suficientemente el concepto de vulnerabilidad, pues se dedica más al análisis de la probabilidad de ocurrencia que al de las inequidades y de las desigualdades sociales" (Araujo, 2015, p. 93).
} 
También cabe señalar que la vulnerabilidad social se expresa en todas las limitaciones que experimentan las personas que viven con VIH-sida, por ejemplo, muchas de ellas no tienen una alimentación adecuada (algunos difícilmente pueden garantizar tres comidas al día); tampoco tienen acceso a un trabajo digno, pues carecen de formación académica, experiencia, recomendaciones laborales y en ocasiones la retribución que reciben es exigua. En el caso de los extranjeros, no tener los documentos al día (visa de trabajo, cédula de extranjería, convalidaciones, trámites, costos, etc.) constituye un factor para la explotación laboral. Pasa lo mismo con los colectivos LGBTIQ+, a quienes se les rechaza por su condición de género. Hoy, todavía hay personas que no cuentan con acceso a vivienda o infraestructura sanitaria, entre otros elementos básicos. Para Adela Cortina (2017) el "sinhogarismo" es:

[...] un problema social sangrante, porque muestra un grado extremo de vulnerabilidad en quien lo padece. Quien no tiene siquiera la protección de un hogar, por precario que sea, no posee ni un mínimo de intimidad para su vida cotidiana, ni goza tampoco de una ínfima protección frente a agresiones externas, frente a tratos degradantes, está a disposición de cualquier descerebrado con ganas de divertirse un rato a su costa, o de cualquier resentido deseoso de volcar en alguien su rencor. Carecer de hogar supone una ruptura relacional, laboral, cultural y económica con la sociedad, es una clara situación de exclusión social. El sinhogarismo es la expresión de una suprema vulnerabilidad. (p. 31)

\section{Vulnerabilidad política al VIH-sida}

Uno de los primeros aspectos para analizar es el Acuerdo 143 de 2005, el cual fue modificado por el artículo 9 del Decreto Distrital 547 de 2016. Lo significativo aquí es que se pasó de un Acuerdo específico para el VIH-sida, a un Decreto genérico que solo indica una reorganización administrativa y 
remite al Acuerdo 641 de 2016 para saber cómo quedó estructurado el sector salud en Bogotá.

El Acuerdo 143, promulgado por el Concejo de Bogotá (2005), era específico para el VIH-sida porque su objeto establecía "disposiciones sobre el manejo de la infección por VIH y del síndrome de inmunodeficiencia adquirida-sida para el Distrito Capital”. Dentro de las instancias de planeación y coordinación del Acuerdo, se creó un Comité Distrital de Promoción de la Salud y Prevención de las Enfermedades de Transmisión Sexual y del Síndrome de Inmunodeficiencia Adquirida (art. 22), el cual se fusionó en el Consejo Distrital de Seguridad Social en Salud Ampliado a través del Acuerdo 641 de 2016. Según la Alcaldía Mayor de Bogotá (2019), este consejo es "el máximo organismo asesor del sector salud en el Distrito Capital y será la instancia de coordinación que posibilite la adecuada ejecución de las políticas públicas en salud" (art. 2). Sin embargo, al revisar sus aportes como ente asesor que ayuda a mejorar la salud de las personas que viven en Bogotá, se evidencian dos cosas: primero, la reglamentación tardía de sus competencias, pues, según la reorganización del sector salud expresada en el Acuerdo 641 de 2016, esto debía ser al término de un año (o sea, en 2017); no obstante, hasta el año 2019 con el Acuerdo 002 del 12 de agosto, fue posible contar con el reglamento interno del Consejo Distrital de Seguridad Social en Salud Ampliado. Segundo, su operabilidad ha sido inexistente pues hasta el año 2018 el Gobierno distrital de turno decidió reactivar este ente asesor (Alcaldía Mayor de Bogotá, 2018).

Todo este dinamismo burocrático que afecta la salud de quienes viven con VIH-sida en Bogotá, se explica en la siguiente figura. 


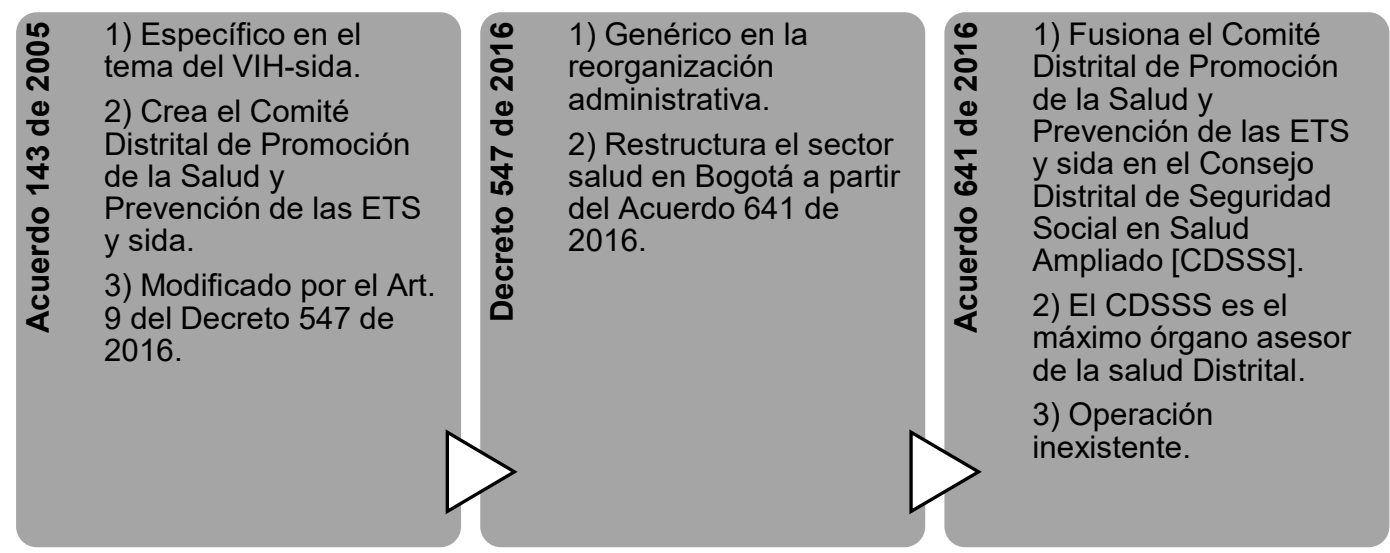

Figura 1. Lógica administrativa de la salud Distrital.

Fuente: elaboración propia a partir de información extraida de la Alcaldía Mayor de Bogotá (2016), Concejo de Bogotá (2005), Concejo de Bogotá (2016).

Por otro lado, los Planes Territoriales ratifican la incapacidad del sistema de salud para garantizar la calidad de vida a las personas que viven con VIH-sida en Bogotá. Por ejemplo, en el periodo 2012-2016 se estableció lo siguiente:

La situación se agrava con factores propios del sistema de salud vigente. Es así como persisten inequidades entre localidades, grupos y regímenes del Sistema de Seguridad Social en Salud, en aspectos que se reflejan en la mortalidad evitable y embarazos en adolescentes; se mantienen barreras de acceso, escasa resolutividad, fragmentación del servicio y desequilibrio entre actores. Los trámites y procesos en la organización del sistema de salud ponen en entredicho la calidad de la respuesta efectiva a las necesidades de la población. El modelo de atención, con enfoque asistencialista, no permite garantizar el derecho a la salud.

(Secretaría Distrital de Salud, 2012, p. 56)

El Plan Territorial de la "Bogotá Humana" (2012-2016) se propuso la defensa efectiva del derecho a la salud, reducir los casos de VIH-sida y el acceso universal a tratamientos. No obstante, la figura 2 muestra un 
aumento progresivo de los casos de VIH-sida durante estos años. Además, las tutelas 5 interpuestas para salvaguardar el derecho a la salud también se incrementaron. Aquí las cifras:

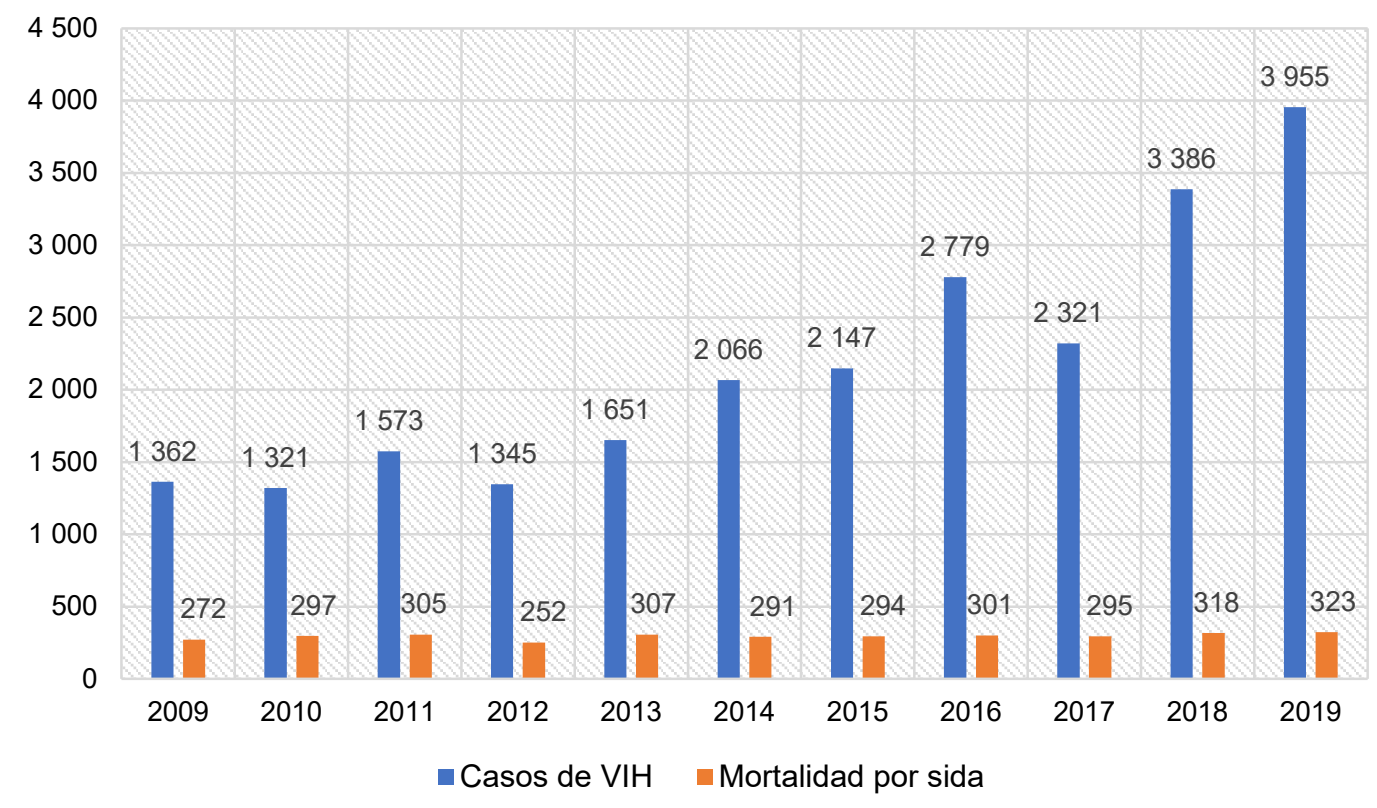

Figura 2. Una década de VIH-sida en Bogotá.

Fuente: elaboración a partir de los datos encontrados en Saludata, 2021.

\footnotetext{
${ }^{5}$ Mecanismo previsto en la Constitución Política de Colombia (1991) para "reclamar ante los jueces, en todo momento y lugar, mediante un procedimiento preferente y sumario, por sí misma o por quien actúe a su nombre, la protección inmediata de sus derechos constitucionales fundamentales, cuando quiera que estos resulten vulnerados o amenazados por la acción o la omisión de cualquier autoridad pública" (art. 86).
}

\section{Análisis}

ISSN: 0120-8454 | e-ISSN: 2145-9169 | DOI: https://doi.org/10.15332/21459169

Vol. 53 N. 099 | julio-diciembre de 2021 


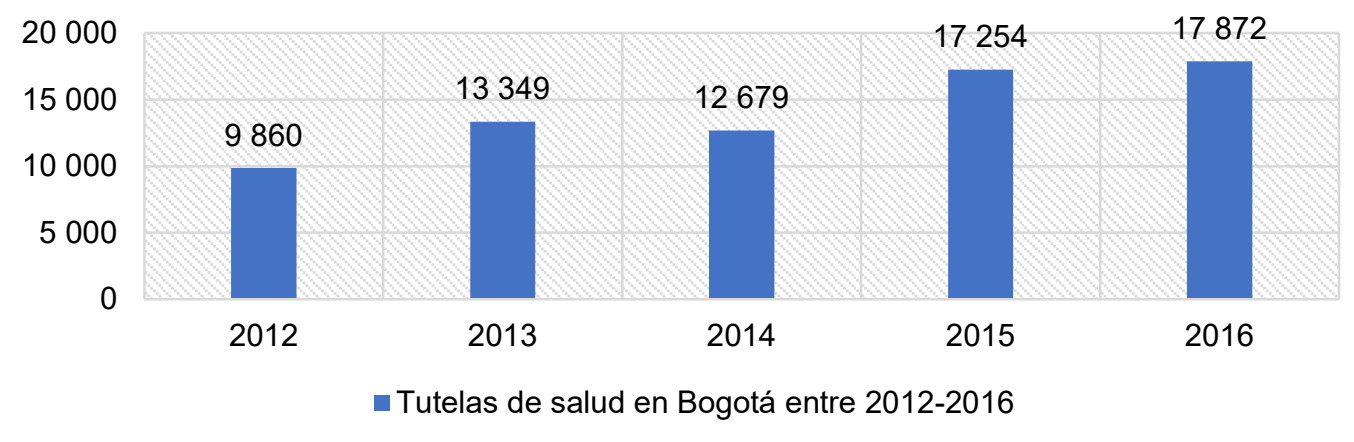

Figura 3. Tutelas de salud en Bogotá entre el 2012 y el 2016.

Fuente: elaboración propia a partir de los datos extraidos de la Defensoría del Pueblo (2014, p. 228; 2016, p. 148; 2017, p. 106).

Cabe señalar que el 16 de febrero de 2015 se promulgó la Ley Estatutaria 1751, por la cual se debía "garantizar el derecho fundamental a la salud, regularlo y establecer sus mecanismos de protección" (Congreso de la República de Colombia, 2015). Esta Ley surge en el país en respuesta a las diversas barreras para acceder al sistema de salud, las cuales suscitaron el aumento en las tutelas, obligando a que la Corte Constitucional de Colombia (2008) le recordara al Estado a través de la Sentencia T-76o/o8, su responsabilidad en garantizar el derecho a la salud. No obstante, aún hoy, sigue en deuda la garantía de este derecho.

Desde otra perspectiva, el Plan Territorial de "Bogotá Mejor para Todos" (2016-2020) manifestó lo siguiente:

El sistema de salud en Bogotá, D. C. atraviesa hoy por una grave crisis que afecta notoriamente su legitimidad social. El desempeño general es fiel reflejo de la fragmentación manifiesta en la falta de coordinación entre entidades del sector, duplicidad de servicios e infraestructura, capacidad instalada ociosa o sobresaturada, servicios no resolutivos y competencia desleal entre prestadores públicos. [...] Tampoco hay una gestión adecuada del riesgo de enfermar y morir con la cual se dé una 
respuesta adecuada al proceso de transición epidemiológica. (Secretaría

Distrital de Salud, 2017, p. 24)

Por esta razón, el Gobierno Distrital adoptó dos “aspectos”, a saber:

El primer aspecto se fundamenta en la Ley Estatutaria 1751 de 2015, que ratifica la salud como derecho fundamental y el Plan Nacional de Desarrollo que ordena avanzar en un nuevo modelo de salud y prestación de servicios, orientados a la atención integral y las redes integradas de servicios. El segundo aspecto se basa en las recomendaciones de la Organización Mundial de la Salud, que sugieren avanzar en modelos de cobertura universal y planes de salud integrales prestados por Redes Integradas de Servicios de Salud (RISS) resolutivas. (p. 24)

Pese a esta ruta de trabajo, las personas con conductas de riesgo aún experimentan estigma, discriminación, violencia de género ${ }^{6}$ y no se ha podido reducir la brecha en la detección temprana del virus. De ahí que se sigan infectando o muriendo por causas asociadas al sida, tal como reflejan los datos de la figura 2 y el número significativo de tutelas presentado a continuación en la figura 4, lo cual deja en firme que las estrategias no responden eficazmente, por el contrario, eternizan la deuda histórica con la salud de quienes viven en Bogotá.

\footnotetext{
6 "De la historia de la epidemia de VIH, hemos visto cómo el estigma y la discriminación afectan negativamente la salud física y mental de las personas y el apoyo social. Igualmente, el estigma y la discriminación pueden conducir a violaciones y abusos significativos de los derechos humanos, dejando a los más vulnerables más atrás. Ciertos idiomas y actitudes, violaciones de la privacidad y enfoques criminales pueden conducir al estigma y la discriminación. [...] Los gobiernos deben trabajar para evitar la creación de puntos de vista o actitudes estigmatizantes, tanto en el ámbito de la atención de salud y de manera más amplia, y deben trabajar para combatir esas actitudes cuando surjan. La experiencia de Onusida es que dicho estigma solo sirve para enviar a las personas y comunidades a la clandestinidad y, en última instancia, amenaza el éxito de cualquier respuesta" (Onusida, 2020, p. 8).
}

\section{Análisis}

ISSN: 0120-8454 | e-ISSN: 2145-9169 | DOI: https://doi.org/10.15332/21459169

Vol. 53 N.o 99 | julio-diciembre de 2021 


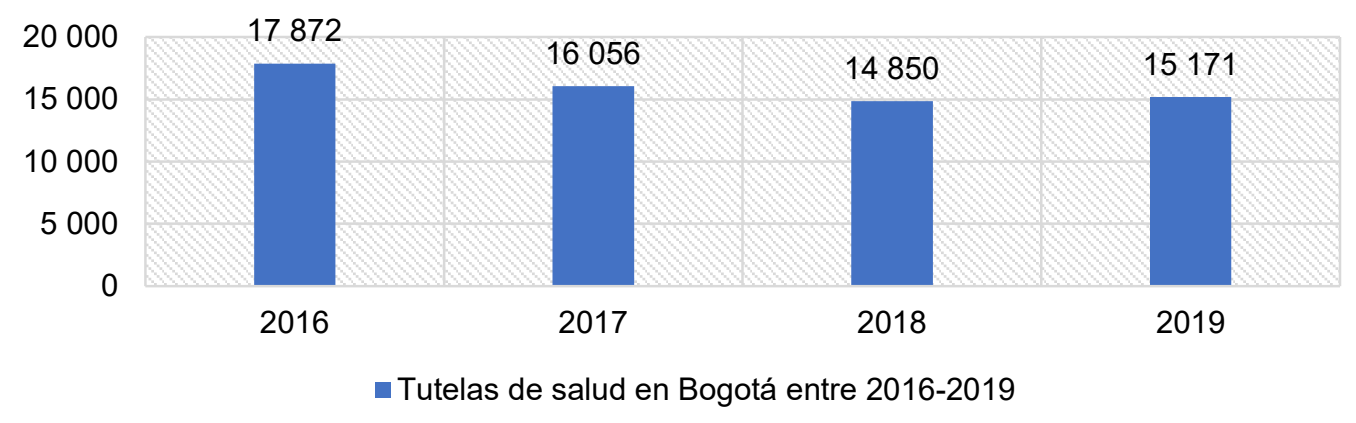

Figura 4. Tutelas de salud en Bogotá entre el 2016 y el 2019.

Fuente: elaboración propia a partir de los datos extraidos de la Defensoría del Pueblo (2017, p. 106), Defensoría del Pueblo (2019, p. 85), Defensoría del Pueblo (2020, p. 125).

El análisis de la política Distrital deja en evidencia que los Planes Territoriales de Salud, desde el año 2012 hasta el 2020, garantizan deficientemente el derecho a la salud; no logran reducir los casos de VIHsida, no aseguran el acceso universal a tratamientos, y no eliminan el estigma, la discriminación y violencia de género hacia las personas con conductas de riesgo.

Estos planes presentan en el papel a un Gobierno distrital aparentemente humanitario, conocedor de una problemática en salud porque ha hecho un diagnóstico y trazado unos lineamientos con objetivos, metas y estrategias pertinentes para transformar el servicio de salud en la capital. Sin embargo, en la praxis, la realidad dista de los documentos y buenas intenciones de los mandatarios de turno; esto queda claro con los datos presentados y la evaluación desde la perspectiva fiscal que hizo la Contraloría de Bogotá (2017) a los Planes Territoriales de Salud de la “Bogotá Humana” y “Bogotá Mejor para Todos”. Las conclusiones de dicha evaluación arrojan los siguientes conceptos:

Los Planes Territoriales de Salud Pública en el Distrito Capital han sido implementados a partir de 16 proyectos de inversión en el Plan de 
Desarrollo Bogotá Humana y 9 proyectos de inversión en el Plan de Desarrollo Bogotá Mejor para Todos. Una vez revisada la información con la que se cuenta en términos de ejecución y cumplimiento de metas, y a pesar de la hoja de ruta definida en la normatividad, se presentan obstáculos para realizar una adecuada articulación entre la narrativa establecida en los documentos y las acciones de política pública que se llevan a cabo, así como de los procesos de seguimiento y evaluación. El principal obstáculo que se evidencia para el proceso de ejecución y cumplimiento de metas, se presenta en que el responsable del sector salud en Bogotá D.C., [Secretaría Distrital del Salud] además de presentar falencias en la presentación de informes y documentos de gestión, hace referencia exclusivamente a la ejecución de los proyectos de inversión sin presentar su correlación con la implementación del Plan Territorial de Salud Pública, esto sin mencionar que pierde de vista el vínculo que debe existir entre los avances alcanzados y su aporte al Plan Decenal de Salud Pública. [...] En términos de gestión fiscal, los principales actores responsables de la implementación del Plan Territorial de Salud Pública se han caracterizado por presentar falencias en el cumplimiento de los principios de eficiencia, eficacia y economía, ya que durante el periodo analizado el fenecimiento de las cuentas no alcanza el 50 \% de los sujetos evaluados, siendo especial la vigencia 2016 debido al proceso de reorganización del sector salud. Algunas de las consecuencias de estas falencias, que en su mayoría se concentran en los componentes de planes, programas y proyectos, así como en el de gestión contractual, se evidencian en los resultados de la gestión administrativa que fueron detallados por cada meta de lo realizado durante el Plan de Desarrollo “Bogotá Humana”. (pp. 209-210)

Con lo anterior, se demuestra una vez más la manera en que la razón humanitaria que justifica las políticas de salud pública en Bogotá determina e incrementa la vulnerabilidad social cuando refuerza el riesgo de infección por VIH o muerte asociada al sida en ciertos grupos sociales. 
En suma, los procesos y factores que se hallaron en el análisis de las políticas públicas, por los cuales se precisa la vulnerabilidad social al VIHsida en Bogotá son los siguientes:

Tabla 2. Procesos y factores que determina la vulnerabilidad al VIH-sida en Bogotá

\begin{tabular}{|c|c|c|}
\hline Factores & Descripción & Procesos \\
\hline $\begin{array}{l}\text { Reorganización del } \\
\text { sector salud }\end{array}$ & $\begin{array}{l}\text { El marco normativo y legal propone } \\
\text { reorganizar el sector salud. }\end{array}$ & $\begin{array}{l}\text { La reorganización es genérica y deja } \\
\text { intacto el núcleo en el cual descansa la } \\
\text { vulnerabilidad a la enfermedad, al tiempo } \\
\text { que legitima la visión biomédica del } \\
\text { sistema. }\end{array}$ \\
\hline $\begin{array}{l}\text { Concepción de la } \\
\text { salud }\end{array}$ & $\begin{array}{l}\text { El marco normativo y legal concibe } \\
\text { la salud como un derecho, pero } \\
\text { también como un servicio público a } \\
\text { cargo del Estado. }\end{array}$ & $\begin{array}{l}\text { Estas visiones son antagónicas; el sistema } \\
\text { privilegia la mercantilización de la salud } \\
\text { [servicio]. }\end{array}$ \\
\hline $\begin{array}{l}\text { Diagnóstico y } \\
\text { respuesta al } \\
\text { problema }\end{array}$ & $\begin{array}{l}\text { Se considera que el marco } \\
\text { normativo y legal identifica } \\
\text { adecuadamente el alcance del } \\
\text { problema que propone el VIH-sida. }\end{array}$ & $\begin{array}{l}\text { La respuesta al VIH-sida sigue siendo } \\
\text { débil, pues no se logra garantizar } \\
\text { plenamente la vida y salud de las } \\
\text { personas que viven con el virus, la } \\
\text { detección temprana y el acceso a } \\
\text { medicamentos, etc. }\end{array}$ \\
\hline Lenguaje normativo & $\begin{array}{l}\text { El VIH-sida es concebido como una } \\
\text { enfermedad ruinosa, catastrófica y } \\
\text { de alto costo (Ley } 972 \text { de 2005). }\end{array}$ & $\begin{array}{l}\text { Esta manera de concebir el virus genera } \\
\text { barreras para la atención de las personas, } \\
\text { al tiempo que legitima el estigma y la } \\
\text { exclusión a nivel social. }\end{array}$ \\
\hline Percepción punitiva & $\begin{array}{l}\text { Queda inexequible el art. } 370 \text { del } \\
\text { código penal colombiano, por el } \\
\text { cual se consideraba la propagación } \\
\text { del VIH-sida como un delito } \\
\text { (Sentencia C-248/19). }\end{array}$ & $\begin{array}{l}\text { Las secuelas de esa percepción punitiva } \\
\text { calaron socialmente para ayudar a } \\
\text { configurar los castigos de odio, el estigma, } \\
\text { la exclusión y otras formas de violencia. }\end{array}$ \\
\hline $\begin{array}{l}\text { Individualización } \\
\text { del riesgo }\end{array}$ & $\begin{array}{l}\text { Desde la aparición del VIH-sida se } \\
\text { propuso la estrategia del } \\
\text { "autocuidado". }\end{array}$ & $\begin{array}{l}\text { Se responsabiliza al individuo por su } \\
\text { estado de salud y del cuidado de los } \\
\text { demás. }\end{array}$ \\
\hline $\begin{array}{l}\text { Desconocimiento } \\
\text { del ser humano }\end{array}$ & $\begin{array}{l}\text { Las políticas públicas desconocen la } \\
\text { realidad del ser humano inmerso en } \\
\text { el mundo del VIH-sida. }\end{array}$ & $\begin{array}{l}\text { Desconocer la realidad que experimentan } \\
\text { las personas que viven con el virus, hace } \\
\text { que las estrategias y respuestas al VIH- } \\
\text { sida sean inoperantes. }\end{array}$ \\
\hline $\begin{array}{l}\text { Marco normativo y } \\
\text { legal }\end{array}$ & $\begin{array}{l}\text { Las políticas públicas presentan a } \\
\text { un Estado aparentemente solidario } \\
\text { y humanitario con quienes viven } \\
\text { con VIH-sida. }\end{array}$ & $\begin{array}{l}\text { Estrategias de control biopolítico para } \\
\text { determinar quien vive y la clase de vida de } \\
\text { pueden vivir. }\end{array}$ \\
\hline
\end{tabular}

Fuente: elaboración propia. 


\section{Consideraciones finales}

Los procesos y factores encontrados en la investigación dejan en evidencia varias cosas; primero, tal parece que los diseñadores y operarios de la política pública del VIH-sida no tienen conciencia de las inconsistencias que subyacen entre lo teórico (marco normativo y legal) y la realidad de las personas que viven con el virus; segundo, las organizaciones de base comunitaria tienen en mente un diagnóstico y enfoque del VIH-sida distinto al de las instituciones de salud pública, lo cual impide un trabajo mancomunado y refuerza la vulnerabilidad social a la enfermedad; tercero, no hay voluntad para transformar la política frente al problema del VIHsida ni por conocer las muy diversas realidades que experimentan quienes viven con el virus.

Por otra parte, al analizar la política pública distrital, se observa que la crisis actual del sistema de salud en el país encuentra sus causas, principalmente, en la ambigüedad de la Constitución Política de 1991 y la reforma planteada por la Ley 100 de 1993. Es decir, la Constitución (1991) afirma que el derecho a la vida es inviolable (art. 11), pero asume la salud como un servicio público a cargo del Estado que debe ser garantizado a todas las personas (art. 49). Dicho de otra manera, cuando se establece la salud como un servicio-negocio y no como un derecho, las garantías para proteger la vida de las personas dependen de sus recursos económicos; de ahí que el Estado no solucione las necesidades insatisfechas de salud que él mismo ha generado.

Asimismo, el nuevo sistema que propuso la Ley 100 (Congreso de la República de Colombia, 1993), reglamenta la mercantilización de la salud en Colombia y atenta contra el derecho a la vida, tal como ha quedado demostrado con las acciones de tutela interpuestas desde el 2012 hasta 2019 (ver gráfica 2 y 3). De igual forma, carece de articulación entre los 
actores que lo componen7 $\mathrm{y}$, generalmente, no favorece el bienestar integral del paciente, puesto que, entre sus necesidades y la prestación del servicio, suele interponerse el interés económico de un sistema que mercantilizó la salud.

En consecuencia, el país cuenta con un sistema que presta servicios asistenciales con ánimo de lucro; sus usuarios son un medio para tal fin, pues entre más afiliados tengan las Entidades Promotoras de Salud (EPS), más Unidad de Pago por Capitación recibirán (Ley 100 de 1993, art. 182), aun negando el servicio de salud. En definitiva, la Ley 100 garantiza el acceso universal a la salud, pero los recursos económicos no son suficientes. Una de las razones es que gracias a la autonomía que esta Ley otorgó a las Entidades Promotoras de Salud (art. 156) e Instituciones Prestadoras de Servicios de Salud (art. 153) y a la ineficiente vigilancia y control de la Superintendencia Nacional de Salud ${ }^{8}$, algunas instituciones públicas y privadas han hecho malversación de los recursos fiscales del presupuesto nacional, de solidaridad y los entes territoriales destinados para la salud, haciendo que el sistema sea insostenible e incompatible con la vida de las personas, su dignidad y sus derechos humanos.

\footnotetext{
7 "Artículo 155: Integrantes del Sistema General de Seguridad Social en Salud. El Sistema General de Seguridad Social en Salud está integrado por: 1. Organismos de dirección, vigilancia y control: a) Los Ministerios de Salud y Trabajo; b) El Consejo Nacional de Seguridad Social en Salud; c) La Superintendencia Nacional en Salud; 2. Los Organismos de administración y financiación: a) Las Entidades Promotoras de Salud; b) Las direcciones seccionales, distritales y locales de salud; c) El Fondo de solidaridad y garantía; 3. Las institucionales Prestadoras de servicios de salud, públicas, mixtas o privadas; 4 . Las demás entidades de salud que, al entrar en vigencia la presente Ley, estén adscritas a los Ministerios de Salud y Trabajo; 5 . Los empleadores, los trabajadores y sus organizaciones y los trabajadores independientes que cotizan al sistema contributivo y los pensionados; 6. Los beneficiarios del Sistema General de Seguridad Social en Salud, en todas sus modalidades; 7. Los Comités de Participación Comunitaria 'Copacos' creados por la Ley 10 de 1990 y las organizaciones comunales que participen en los subsidios de salud". (Congreso de la República de Colombia, 1993)

${ }^{8}$ Tiene como misión "proteger los derechos de los usuarios del Sistema General de Seguridad Social en Salud mediante la inspección, vigilancia, control y el ejercicio de la función jurisdiccional y de conciliación de manera transparente y oportuna" (Supersalud, 2020).
}

\section{Análisis}

ISSN: 0120-8454 | e-ISSN: 2145-9169 | DOI: https://doi.org/10.15332/21459169

Vol. 53 N.o 99 | julio-diciembre de 2021 


\section{Recomendaciones}

$\mathrm{Al}$ finalizar este recorrido investigativo se puede afirmar que la respuesta política que en Bogotá y Colombia se ha dado a la realidad vulnerable y vulnerada del VIH-sida, dinamiza una jerarquía de sufrimiento que legitima sistemáticamente formas de violencia estructural hacia los grupos sociales más desposeídos, al punto de anular su existencia, sus derechos y su dignidad humana. Por tal motivo, se brindan algunas recomendaciones para reorientar las políticas públicas en materia de VIH-sida en Bogotá, las cuales surgen principalmente de quienes participaron en el ejercicio investigativo. Ellos, desde su experiencia de vida comunitaria y profesional, expresaron su sentir.

Tabla 3. Recomendaciones de las instituciones y organizaciones de base comunitaria para mejorar la política pública de VIH-sida en Bogotá

\section{Entrevistado n. 02}

“1) Que el tomador de decisiones, el que hace la política, haga el esfuerzo de conocer la situación del ser humano inmerso en el VIH-sida; 2) Se debe asegura una visión bioética en la toma de decisiones de la política pública; la ética no se consulta, consultan al abogado para saber si el marco normativo está bien, al economista para ver qué costo genera, pero no consultan las implicaciones éticas; 3) Que no se tomen decisiones con intereses particulares; es necesario limpiar la política pública para poner al ser humano en el centro y se logre responder efectivamente a sus necesidades. Se deben tomar los principios bioéticos de beneficencia, justicia, no-maleficencia y plasmarlos en las políticas".

\section{Entrevistado $\mathrm{n} .03$}

“1) La continuidad; la política y las estrategias siempre están sujetas a presupuestos, entonces, la estrategia termina en octubre y mientras se hace todo el proceso de contratación y se renueva, se tienen periodos muertos que muchas veces echan para atrás todo lo que se hace con la población; 2) La rotación de los funcionarios es muy alta. Se entrenan a personas en asesorías y cuando vas a ver, están haciendo otras cosas o no están haciendo lo que tienen que hacer. Los contratos de prestación de servicio facilitan dicha rotación; 3) Mayor participación de los tomadores de decisiones en las reuniones de trabajo trimestrales; 4) Mayor involucramiento del concejo de Bogotá en el tema de VIH, pues allí hay oposición de algunos grupos".

\section{Entrevistado n. 4}

"Creo que se debe trabajar con las personas la capacidad del riesgo que lo acompaña para descubrir los límites del riesgo que uno debe y puede asumir".

\section{Entrevistado n.o 5}

"Reconfiguraciones estructurales. Por ejemplo, debe haber un programa distrital de VIH-sida. Esto debe tener un doliente, debe tener un hacedero institucional. Tal como sucede con la política LGTBI, antes habían acciones de respeto y no discriminación, pero solo hasta que administrativamente e institucionalmente se configuraron dentro de la función pública, dentro del ejecutivo, se pudo hacer. Ya 
hubo una dirección de diversidad sexual que se encargó de darle una técnica, ya hubo una sub-dirección de LGTBI para asuntos sociales. Eso que logró la política LGTBI es adentrarse dentro del sistema institucional, alguien que responda. Necesitamos una política que dentro de sus acciones incluya lo institucional pero no puede ser visto bajo la voluntad de una persona, bajo la sensibilidad de un funcionario. Una política pública es política cuando es capaz de estar en la agenda pública, pero también cuando se convierte en un asunto gubernamental que trasciende. La política pública traerá consigo todo lo que se necesita para que trascienda".

Fuente: elaboración propia.

Otro aporte que resulta interesante para reorientar la política pública preventiva en materia de VIH-sida en Bogotá, es el que hace Onusida (2020) en relación con la emergencia sanitaria por la COVID-19 que actualmente se vive a nivel mundial.

1. Involucrar a las comunidades afectadas desde el inicio en todas las medidas de respuesta para generar confianza, garantizar acciones adecuadas y eficientes, evitar daños indirectos o no intencionados, y garantizar el intercambio frecuente de información.

2. Combatir todas las formas de estigma y discriminación, incluyendo las basadas en raza, contacto social, profesión (trabajadores de la salud) y aquellas dirigidas a grupos marginados que les impiden acceder a la atención.

3. Garantizar el acceso gratuito o con costos accesibles a tamizajes, pruebas de detección y atención para las personas más vulnerables y difíciles de alcanzar.

4. Eliminar las barreras que enfrentan las personas en la protección de su propia salud y la de sus comunidades: miedo al desempleo, costos de atención médica, presencia de noticias falsas e información errónea, falta de infraestructura de saneamiento, etc.

5. Las restricciones para proteger la salud pública deben ser de duración limitada, proporcionadas, necesarias y basadas en evidencia y en coordinación con las instancias judiciales. Establecer excepciones cuando sea preciso para los grupos vulnerables y para aliviar las consecuencias de tales restricciones. Las prohibiciones 
totales obligatorias rara vez son efectivas o necesarias. Las personas no deben ser penalizadas por infringir las restricciones.

6. Los países deben trabajar para apoyarse mutuamente y así poder garantizar que ningún territorio se quede atrás, compartiendo información, conocimiento, recursos y experiencia técnica.

7. Apoyar y proteger a las personas trabajadoras de la salud. Ser considerados el uno con el otro. Unir y apoyar los esfuerzos que generan confianza y amplifican la solidaridad, en lugar de sancionar.

\section{Referencias}

Alcaldía Mayor de Bogotá. (noviembre 6, 2013). Decreto 507. Por el cual se modifica la Estructura Organizacional de la Secretaría Distrital de Salud de Bogotá, D.C. http://www.saludcapital.gov.co/Documents/Decreto 507\%20Estructura\%20SDS. pdf

Alcaldía Mayor de Bogotá. (diciembre 7, 2016). Decreto 547. Por medio del cual se fusionan y reorganizan las Instancias de Coordinación con fundamento en las facultades extraordinarias otorgadas al Alcalde Mayor de Bogotá por el artículo 118 del Acuerdo 645 de 2016, y se dictan otras disposiciones. https://www.serviciocivil.gov.co/portal/sites/default/files/documentos/Decreto Distrital 5472016 InstanCoordina.pdf

Alcaldía Mayor de Bogotá. (2018). Alcalde Enrique Peñalosa reactiva el Consejo Distrital de Seguridad Social en Salud. Secretaría de Salud. http://www.saludcapital.gov.co/Paginas2/Noticia Portal Detalle.aspx?IP=467

Alcaldía Mayor de Bogotá. (agosto 12, 2019). Acuerdo oo2. Por el cual se adopta el Reglamento Interno del Consejo Distrital de Seguridad Social en Salud Ampliado CDSSS.

http://www.saludcapital.gov.co/Inst_Coordinacion/CDSSS/Normativa/Reglamen to Int CDSSS Acuerdo 002.pdf

Araujo, R. (2015). Vulnerabilidad y riesgo en salud: ¿̇dos conceptos concomitantes? Revista Novedades en Población, 11(21), 89-96. 
Asamblea Nacional Constituyente. (1991). Constitución Política de Colombia.

http://www.secretariasenado.gov.co/senado/basedoc/constitucion_politica 1991. $\underline{\mathrm{html}}$

Castro, A. y Farmer, P. (2003). El sida y la violencia estructural: La culpabilización de la víctima. Cuadernos de Antropología Social, 17, 29-47.

Congreso de la República de Colombia. (16 de febrero, 2015). Ley Estatutaria 1751 de 2015. Por medio de la cual se regula el derecho fundamental a la salud y se dictan otras disposiciones.

https://www.minsalud.gov.co/Normatividad_Nuevo/Ley\%201751\%20de\%202015. pdf

Concejo de Bogotá. (marzo 18, 2005). Acuerdo 143. Por el cual se dictan unas disposiciones en materia de prevención, control y tratamiento del síndrome de inmunodeficiencia humana VIH y del sida en Bogotá, D.C.

http://www.saludcapital.gov.co/Inst Coordinacion/ETS SIDA/Normativa/Adopc ion Acuerdo 143 2005.pdf

Concejo de Bogotá. (abril 6, 2016). Acuerdo 641. Por el cual se efectúa la reorganización del sector salud de Bogotá, Distrito capital, se modifica el acuerdo 257 de 2006 y se expiden otras disposiciones.

http://www.saludcapital.gov.co/Documents/Acuerdo 641 de 20166.pdf

Congreso de la República de Colombia. (diciembre 23, 1993). Ley 100. Por la cual se crea el sistema de seguridad social integral y se dictan otras disposiciones. DO. 41.148. http://www.secretariasenado.gov.co/senado/basedoc/ley 0100 1993.html

Corte Constitucional de Colombia. (2008). Derecho a la salud-Es un derecho fundamental. https://www.corteconstitucional.gov.co/relatoria/2008/t-76008.htm

Cortina, A. (2017). Aporofobia, el rechazo al pobre: Un desafio para la democracia. Paidós.

Contraloría de Bogotá. (2017). Plan Territorial de Salud de Bogotá. Evaluación desde la perspectiva fiscal al plan de desarrollo "Bogotá humana" y una aproximación a “Bogotá mejor para todos”. Contraloría de Bogotá.

http://www.contraloriabogota.gov.co/sites/default/files/Contenido/Informes/Estr ucturales/Salud/2012-2016\%20Plan\%20Territorial\%20de\%20Salud\%20PAE2017.pdf 
Creswell, J. (1998). Qualitative inquiry \& research design choosing among five traditions. Sage Publications.

Defensoría del Pueblo. (2014). La tutela y los derechos a la salud y a la seguridad social 2013. Defensoría del Pueblo.

Defensoría del Pueblo. (2016). La tutela y los derechos a la salud y a la seguridad social 2015 (10 ${ }^{\mathrm{a}}$ ed). Defensoría del Pueblo.

Defensoría del Pueblo. (2017). La tutela y el derecho a la salud 2016 (11 ${ }^{\mathrm{a}}$ ed). Defensoría del Pueblo.

Defensoría del Pueblo. (2019). La tutela y los derechos a la salud y a la seguridad social 2018 (13 ${ }^{\mathrm{a}}$ ed). Defensoría del Pueblo.

Defensoría del Pueblo. (2020). La tutela y los derechos a la salud y a la seguridad social 2019 ( $14^{\mathrm{a}}$ ed). Defensoría del Pueblo.

El Tiempo. (2002). Primera zona de tolerancia.

https://www.eltiempo.com/archivo/documento/MAM-1320701

Fassin, D. (2007). When Bodies Remember: experiences and politics of aids in South Africa. University of California Press.

Link, B. y Phelan, J. (2001). Conceptualizing stigma. Annual Review of Sociology, 27, $363-385$.

Ministerio de Salud y Protección Social. (2014). Informe GARPR. Seguimiento de la Declaración de compromiso sobre el VIH/sida.

http://www.unaids.org/sites/default/files/country/documents//COL narrative r eport 2014.pdf

Onusida. (2020). Los Derechos Humanos en tiempos de COVID-19. Lecciones del VIH para una respuesta efectiva dirigida por la comunidad.

https://www.unaids.org/sites/default/files/media asset/human-rights-and-covid19 es.pdf

Onusida. (2021). Estimaciones sobre el VIH y el sida. http://www.unaids.org/es/regionscountries/countries/colombia

Osuna, J y Márquez, C (2000). Guía para la evaluación de políticas públicas. Instituto de Desarrollo Regional (IDR).

Análisis

ISSN: 0120-8454 | e-ISSN: 2145-9169 | DOI: https://doi.org/10.15332/21459169

Vol. 53 N.o 99 | julio-diciembre de 2021 
Presidencia de la República de Colombia. (febrero 22, 1991). Decreto 559. Por el cual se reglamentan parcialmente las Leyes o9 de 1979 y 10 de 1990, en cuanto a la prevención, control y vigilancia de las enfermedades transmisibles, especialmente lo relacionado con la infección por el Virus de Inmunodeficiencia Humana, VIH, y el Síndrome de Inmunodeficiencia Adquirida, sida, y se dictan otras disposiciones sobre la materia. D O No. 39.699, 1-16.

Saludata. (2021). Tasa de notificación VIH/sida y tasa de mortalidad asociada a sida en Bogotá. https://saludata.saludcapital.gov.co/osb/index.php/datos-desalud/enfermedades-trasmisibles/incidenciaymortalidadvih-sida/

Secretaría Distrital de Salud. (2012). Plan Territorial de Salud de Bogotá Distrito Capital 2012-2016.

http://www.saludcapital.gov.co/CTDLab/Antecedentes\%20Normativos/PLAN\%2 OTERRITORIAL\%20DE\%20SALUD\%20MAYO\%202012\%2002.pdf

Secretaría Distrital de Salud. (2017). Plan Territorial de Salud para Bogotá, D.C., 20162020 .

http://www.saludcapital.gov.co/Documents/Plan_Territorial_Salud_2016_2020. pdf

Sontag, S. (2003). La enfermedad y sus metáforas; El sida y sus metáforas. Taurus.

Supersalud. (julio 10, 2020). Misión y visión. https://www.supersalud.gov.co/esco/nuestra-entidad/estructura-organica-y-talento-humano/mision-y-vision

UNFPA y Ministerio de la Protección Social. (2008). Factores de Vulnerabilidad a la Infección por VIH en mujeres. https://colombia.unfpa.org/es/publications/factores-de-vulnerabilidad-lainfección-por-vih-en-mujeres 